\title{
The role of the REG4 gene and its encoding product in ovarian epithelial carcinoma
}

\author{
Shuo Chen ${ }^{1}$, Wen-Feng Gou², Shuang Zhao ${ }^{2}$, Zhe-Feng Niu², Yang Zhao ${ }^{1}$, Yasuo Takano ${ }^{3}$ and Hua-Chuan Zheng ${ }^{2^{*}}$
}

\begin{abstract}
Background: Although its biological function remains poorly understood, REG4 is reported to be a potent activator of the EGFR/Akt/AP-1 signaling pathway in colon cancer cells and closely linked with the inhibition of apoptosis.

Methods: SKOV3 cells were transfected with a REG4-expressing plasmid or treated with recombinant REG4. We then analyzed proliferation, cell cycle, apoptosis, invasion and metastasis or expression of related molecules. REG4 expression was examined in normal ovarian tissue, benign and borderline tumors, and cancers by immunohistochemistry or real-time PCR.
\end{abstract}

Results: REG4 overexpression and the recombinant protein inhibited cell apoptosis, enhanced $\mathrm{G}_{2} / \mathrm{S}$ progression, proliferation, migration and invasion. Furthermore, expression of Wnt5a, p70s6k, survivin and VEGF expression was increased, while Bax expression was decreased at both the mRNA and protein levels compared to control or mock cells $(P<0.05)$. REG4 mRNA levels were higher in benign tumors and primary cancer compared to those in normal ovarian tissue $(P<0.05)$ while, REG4 protein expression was higher in all three tumor types than that in normal ovarian tissue $(P<0.05)$. Higher REG4 mRNA expression was observed in mucinous carcinomas than serous carcinomas $(P<0.05)$, and in well- and moderately-differentiated carcinomas than poorly-differentiated carcinomas $(P<0.05)$. Survival analysis revealed an inverse relationship between REG4 expression and cumulative or relapse-free survival rates of the patients with ovarian cancer as an independent factor $(P<0.05)$.

Conclusions: Our findings indicate that aberrant REG4 expression plays an essential role in early ovarian carcinogenesis and is closely linked to mucinous ovarian tumors, differentiation and adverse prognosis of ovarian cancer by modulating proliferation, apoptosis, migration and invasion.

Keywords: Ovarian cancer, REG4, Aggressive phenotypes, Pathobiological behavior, Prognosis

\section{Background}

Ovarian cancer is one of the leading causes of death due to cancer in women worldwide. The 5-year survival rate for all stages of ovarian cancer is $35-38 \%$. Due to the lack of effective methods for early diagnosis, most ovarian cancers are only diagnosed at an advanced stage. As such, it is a serious threat to women's health. Ovarian cancers are believed to originate in the ovarian epithelium, with risk factors such as genetic mutations and family history $[1,2]$. An improved understanding of the changes in gene expression and associated molecular mechanisms during ovarian carcinogenesis, as well as identification of novel biomarkers and targets

\footnotetext{
* Correspondence: zheng_huachuan@hotmail.com

${ }^{2}$ Department of Biochemistry and Molecular Biology, College of Basic

Medicine, China Medical University, Shenyang 110001, China

Full list of author information is available at the end of the article
}

for diagnosis and treatment may result in improvements in diagnosis, treatment and prevention of ovarian cancer.

Regenerating (REG) protein is induced during regeneration of pancreatic islets and belongs to the calciumdependent lectin (C-type lectin) gene superfamily. It encodes a group of small multifunctional secretory proteins which function as acute phase reactants, lectins, anti-apoptotic factors and growth agents, and include growth factors for pancreatic $\beta$-cells, neural cells and epithelial cells in the digestive system. These proteins are primarily involved in cell proliferation and differentiation, inflammation, diabetes and carcinogenesis. To date, three subtypes of the REG gene have been identified in humans: REG1 ( $1 \alpha$ and 1B); REG3 (III and HIP/PAP); and REG4 [3-5]. REG4, which is located on human chromosome 
1q12-q21, with three variants produced by alternative splicing [6], was identified by high-throughput sequencing of a cDNA library from ulcerative colitis tissues, implying that it has a central role in initiating the multi-step process of colorectal carcinogenesis.

Studies in colon cancer cell lines showed that REG4 expression was enhanced by stimulation with transforming growth factor (TGF) $\alpha$, EGF, bFGF and HGF [7], and in hepatocellular carcinoma cell lines by stimulation with TGF- $\beta$ [8]. Furthermore, REG4 has been reported to be a potent activator of the epidermal growth factor receptor/Akt kinase/activator protein-1 (EGFR/Akt/AP-1) signaling pathway, leading to increased expression of Bcl-2, Bcl-xl and survivin, which are associated with apoptosis inhibition [9]. Treatment with recombinant REG4 protein protected normal intestinal crypt cells from ionizing radiation (IR)-induced apoptosis by increasing expression of Bcl-2, Bcl-xL and survivin; whereas overexpression of REG4 in human colorectal cancer (CRC) cells was associated with increased resistance to IR-induced apoptosis. REG4 has also been found to induce expression of matrix metalloproteinase-7, which is involved in liver metastasis [10]. Naito et al. [11] suggested that nuclear CDX2 regulates REG4 transcription by binding to its $5^{\prime}$ flanking region. $\mathrm{Li}$ et al. [12] reported that proteoglycan from Phellinus linteus might suppress CRC cells by inhibiting the REG4/EGFR/Akt signaling pathway.

In our previous study, REG4 mRNA and protein expression levels were found to be increased in gastric intestinal metaplasia compared to those in gastric cancer and normal mucosa; higher serum REG4 levels were observed in patients with gastric cancer compared to healthy individuals; and REG4 was expressed more frequently in signet ring cell carcinoma, which closely correlated with MUC-2, and MUC-5 AC expression [13]. Expression of REG4 in CRC cells was significantly lower than in adjacent non-neoplastic mucosa or adenoma, inversely correlated with poor differentiation and venous invasion, and was positively linked to MUC2 expression and EGFR phosphorylation at Tyr1068 [14]. Wang et al. [15] found that expression of both REG4 mRNA and protein in glioma tissues was significantly higher than that in corresponding non-neoplastic brain tissues, and that increased expression of REG4 was significantly associated with advanced pathological grade and low Karnofsky performance score of gliomas. Here, we investigated the effect of REG4 overexpression and recombinant REG4 on the proliferation, apoptosis, invasion and migration of ovarian cancer cell lines, and explored the related mechanisms. In addition, we examined REG4 expression in normal ovarian tissue, benign and borderline ovarian tumors, and primary and metastatic cancers, and compared our findings with the clinicopathological and prognostic parameters of tumors surgically resected from the patients with ovarian cancer.

\section{Methods}

\section{Cell culture and transfection}

Ovarian cancer cell lines: CAOV-3 (serous adenocarcinoma); OVCAR3 (serous cystadenocarcinoma); SKOV3 (papillary serous cystadenocarcinoma); HO8910 (serous cystadenocarcinoma); HO8910-PM (invasive adenocarcinoma); and ES-2 (clear cell carcinoma) were purchased from ATCC (Manassas, VA, USA), SKOV3/DDP (cisplatin-resistant SKOV3) was purchased from the Tumor Cell Bank of Chinese Academy of Medical Science (Peking, China). H08910, H08910-PM, OVCAR3 and SKOV3/DDP were maintained in RPMI 1640; CAOV3 was maintained in DMEM; ES-2 and SKOV3 were maintained in McCoy's 5A, all mediums were supplemented with $10 \%$ fetal bovine serum (FBS), $100 \mathrm{U} / \mathrm{mL}$ penicillin and $100 \mu \mathrm{g} / \mathrm{mL}$ streptomycin, in a humidified atmosphere of $5 \% \mathrm{CO}_{2}$ at $37{ }^{\circ} \mathrm{C}$. The cells were seeded in dishes $24 \mathrm{~h}$ before transfection with $p$ CI-REG4 (kindly donated by Prof. Akira Sugawara; Department of Advanced Biological Sciences for Regeneration, Tohoku University, Japan). Cells were treated with recombinant REG4 (BioVendor, Asheville, NC, USA), or transfected with $p C I-R E G 4$ (SKOV3/REG4) or pCI vector (Mock). Transfected cells were selected using $500 \mathrm{mg} / \mathrm{L}$ G418 according to the manufacturer's instructions (QIAGEN, Valencia, CA, USA).

\section{Cell viability assay}

Briefly, $2.0 \times 10^{3}$ cells/well was seeded on 96-well plates. After cells were adhered at $37{ }^{\circ} \mathrm{C}$ in an atmosphere of $5 \% \mathrm{CO}_{2}, 10 \mu \mathrm{L}$ of CCK-8 (Cell Counting Kit-8; Dojindo, Mashikimachi, Japan) solution was added to each well at different time-points ( $0 \mathrm{~h}, 12 \mathrm{~h}, 24 \mathrm{~h}$, and $48 \mathrm{~h})$ and the plates were incubated for a further $3 \mathrm{~h}$. The number of viable cells was counted by measuring the absorbance at $450 \mathrm{~nm}$ using a microplate reader.

\section{Flow cytometric cell cycle analysis}

After incubation at $37{ }^{\circ} \mathrm{C}$ in an atmosphere of $5 \% \mathrm{CO}_{2}$ for $48 \mathrm{~h}$, cells were detached by trypsinization, collected, washed twice with PBS and fixed in $5 \mathrm{~mL}$ ice-cold ethanol for at least $2 \mathrm{~h}$. The cells were again washed twice with PBS and incubated with $500 \mu \mathrm{L}$ RNase $(0.25 \mathrm{mg} / \mathrm{mL})$ for $30 \mathrm{~min}$ at $37^{\circ} \mathrm{C}$. Cells were pelleted and resuspended in propidium iodide (PI) at a concentration of $50 \mu \mathrm{g} / \mathrm{mL}$ and incubated in the dark for $30 \mathrm{~min}$ at $4{ }^{\circ} \mathrm{C}$. Cell cycle analysis was performed by analyzing PI staining levels by flow cytometry.

\section{Flow cytometric apoptosis assay}

Cell apoptosis was determined by PI and Annexin V-FITC staining (KeyGEN Biotech, Nanjing, China). In brief, cells were incubated for $48 \mathrm{~h}$, washed twice with ice-cold PBS, resuspended at a density of $1 \times 10^{6}$ cells $/ \mathrm{mL}$ in $1 \times$ Binding Buffer and then incubated with $200 \mu \mathrm{L} 1 \times$ Binding Buffer 
containing $10 \mu \mathrm{L}$ FITC-Annexin V. Samples were gently vortexed and incubated for $15 \mathrm{~min}$ at $25^{\circ} \mathrm{C}$ in the dark, then $300 \mu \mathrm{L} 1 \times$ Binding Buffer and $5 \mu \mathrm{L}$ PI was added to each tube. Samples were gently vortexed and incubated for a maximum of $1 \mathrm{~h}$ at $25^{\circ} \mathrm{C}$ in the dark. Flow cytometry was performed within $1 \mathrm{~h}$ of incubation.

\section{Wound healing assay}

Cells were seeded at a density of $1.0 \times 10^{6}$ cells/well in 6-well culture plates. After reaching confluence, each cell monolayer was scraped with a $200 \mu \mathrm{L}$ pipette tip to create a scratch, washed three times with PBS, and cultured in FBS-free medium. Cells were photographed at $0,12,24$, and $48 \mathrm{~h}(n=3)$ and the scratch area was measured using Image software (National Institutes of Health, Bethesda, MD, USA). The wound healing rate $=($ area of original wound-area of actual wound at different times)/ area of original wound $\times 100 \%$.

\section{Cell invasion assays}

Cells $\left(5 \times 10^{5}\right)$ were seeded in the top chamber of Matrigel-coated transwell plates (BD Bioscience, San Jose, CA, USA) with serum-free McCoy's 5A medium. The lower compartment of the chamber contained $10 \% \mathrm{v} / \mathrm{v}$ FBS as a chemoattractant. After incubation for $48 \mathrm{~h}$, cells on the membrane were scrubbed, washed with PBS, fixed in $100 \%$ methanol and stained with Crystal violet dye to measure invasion.

\section{Selection of patient tissue samples}

Samples of normal ovarian tissue, ovarian epithelial benign tumors (serous cystadenoma and mucinous cystadenoma) and borderline tumors, primary and metastatic cancers in the omentum were collected from surgical resections between January 2003 and December 2011 at Department of Gynecology, The First Affiliated Hospital of China Medical University, Shenyang, China. The average age at surgery was 51.2 years (range $20-81$ years). The median age (56 years) was chosen as the divider in Table 2 and Additional file 1: Table S2. The majority of samples were routinely prepared for storage in pathological blocks; the remaining samples were frozen immediately in liquid nitrogen and stored at $-80{ }^{\circ} \mathrm{C}$ until required. In total, 123 samples were fresh-frozen for RT-PCR analysis, while 337 samples were fixed in paraffin for immunostaining analysis (details can be found in Additional file 1: Table S1). Each ovarian cancer was staged according to the International Federation of Gynecology and Obstetrics (FIGO) staging system and histology was defined according to World Health Organization (WHO) classification system. Classification of the differentiation classes of the samples (HE staining) was evaluated by experienced physiologists according to the tumor cell differentiation grades. None of the patients had undergone chemotherapy, radiotherapy or adjuvant treatment prior to surgery. Patients were followed up by consulting their case documents and by telephone. Written informed consent was provided by each participant. The study protocols conformed to the standards set by the Declaration of Helsinki and were approved by China Medical University Ethics Committee.

\section{Western blot analysis}

Protein was extracted in RIPA lysis buffer and its concentration was determined using a protein assay kit (Bio-Rad, Hercules, CA, USA). The denatured protein was separated by $10 \%$ sodium dodecyl sulfate-polyacrylamide gel electrophoresis (10\% SDS-PAGE) and transferred to a Hybond membrane. The membranes were blocked overnight in $5 \%$ skimmed milk in Tris-buffered saline with Tween 20 (TBST, 10 mM Tris-HCl, $150 \mathrm{mM} \mathrm{NaCl}, 0.1$ \% Tween 20). For immunoblotting, the membranes were incubated for $1 \mathrm{~h}$ with antibodies against the following proteins: REG4 (RD Systems Inc, Minneapolis, MN, USA); Wnt5a (Santa Cruz Biotechnology, Dallas, TX, USA); phosphorylated p70 s6k (T421/s424; Cell Signaling, Danvers, MA, USA); Bax (Santa Cruz Biotechnology); survivin (Santa Cruz Biotechnology); and VEGF (Santa Cruz Biotechnology). The membranes were then rinsed with TBST and incubated with IgG conjugated to horseradish peroxidase (HRP; Dako, Carpinteria CA, USA) for $1 \mathrm{~h}$. The bands were visualized using a Fuji 4000 imaging system (Fuji, Tokyo, Japan) after applying electrochemiluminescent (ECL) detection reagents (Santa Cruz Biotechnology). After detection, the membranes were washed with Western blot (WB) Stripping Solution (pH2-3, Nacalai, Tokyo, Japan) for $20 \mathrm{~min}$ and treated, as described above, using mouse GAPDH antibody (Sigma-Aldrich St. Louis, MO, USA) as an internal control.

\section{Real-time reverse transcriptase-polymerase chain reaction} (real-time RT-PCR)

Total RNA was extracted from the cell lines using QIAGEN RNeasy mini kit (QIAGEN) according to the manufacturer's protocol; then $2 \mu \mathrm{g}$ of total RNA was used to synthesize cDNA using AMV reverse transcriptase and random primer (Takara, Ostu, Japan) and then subjected to real-time PCR examination using the SYBR Premix Ex Taq $^{\text {TI II }}$ II kit (Takara) according to the manufacturer's protocol. The oligonucleotide primers for RT-PCR were synthesized by Takara and are listed in Additional file 1: Table S4.

\section{Immunohistochemistry (IHC)}

Tissue samples were deparaffinized with xylene, rehydrated with alcohol, and subjected to antigen retrieval in target retrieval solution (TRS; Dako) for $15 \mathrm{~min}$ by microwave oven irradiation (Oriental Rotor Ltd. Co., Tokyo, Japan). Non-specific binding was prevented in $5 \%$ bovine serum albumin (BSA) for $5 \mathrm{~min}$. The 
sections were incubated with goat anti-human REG4 antibody (1:50) or rabbit-anti-(human) Ki-67 antibody (1:50; Dako) for 15 min and then treated with anti-goat or anti-rabbit conjugated to HRP (1:100; Dako) for $15 \mathrm{~min}$. After each treatment, the slides were washed three times with TBST for $1 \mathrm{~min}$, and the proteins were visualized with 3, 3'-diaminobenzidine (DAB). All incubations were performed in a microwave oven, to allow intermittent irradiation, as previously described [16]. After counterstained with Mayer's hematoxylin, the sections were dehydrated, cleared and mounted. Negative controls were prepared by omitting the primary antibody.

One hundred cells were randomly selected and counted from five representative fields of each section by three independent observers (CS, YZ, and ZHC). Any inconsistencies were checked by three observers until a final agreement was reached. Positive expression was graded as follows: $0=$ negative; $1=1-49 \% ; 2=50-74 \% ; 3 \geq 75 \%$. The staining intensity score was graded as follows: 1 = weak; 2 = intermediate; 3 = strong. The grade and score for REG4 or Ki-67 were multiplied to obtain a final expression score as follows: $-=0 ;+=1-2 ;++=3-4 ;+++=6-9$.

\section{Measurement of cancer antigen 125 (CA-125)}

Quantitative Chemiluminescence Immunoassay kits (Gentaur, Paris, France) were used to detect serum CA-125. Briefly, $50 \mu \mathrm{l}$ of standard (0-1000 U/mL) specimen or control samples were dispensed into appropriate wells in a microtiter plate. Enzyme conjugate reagent $(100 \mu \mathrm{L})$ was added to each well and gently mixed, and the plate was incubated for $60 \mathrm{~min}$ at room temperature. The wells were rinsed and flicked with wash buffer and residual water droplets were removed by striking the well sharply onto absorbent paper. Finally, chemiluminescence substrate solution $(100 \mu \mathrm{L})$ was added to each well, mixed gently and the absorbance was measured.

\section{Statistical analysis}

Statistical analysis was performed using SPSS v. 10.0 software. Spearman's rank correlation coefficient was used to analyze rank data, and Mann-Whitney U-test was used to differentiate the means between different groups. Kaplan-Meier survival plots were generated and comparisons between survival curves were made using Log-rank statistics. Multivariate analysis of parameters such as age, pathological classification, FIGO staging, differentiation and Ki-67 expression was carried out using Cox's proportional hazard model. A $P$-value $<0.05$ was considered to indicate statistical significance.

\section{Results}

REG4 mRNA was found to be expressed at a high level in CAOV3, SKOV3/DDP, HO8910, HO8910-PM cell lines compared with those in ES-2, SKOV3 and OVCAR3 cell lines (Fig. 1a). REG4 protein was expressed at a high level in CAOV3, HO8910 and HO8910-PM cells compared with those in the other cell lines (Fig. 1b). In addition, after treatment with recombinant protein REG4 (50 nM), SKOV3 cell growth was significantly increased (Fig. 1c), compared with that of normal SKOV3 cells (CTR). To elucidate the role of REG4 in ovarian cancer, SKOV3 cells were transfected with a REG4-expressing plasmid and analyzed by realtime RT-PCR (Fig. 1d) and Western blotting (Fig. 1e). Subsequent assays compared the treated SKOV3 cells to control or mock cells (cells transfected with pCI-REG4Mut plasmid) and showed significant increases in cell growth (proliferation assay; $P<0.05$; Fig. 1f); $G_{2} / S$ progression (flow cytometric cell cycle analysis; $P<0.05$; Fig. 2a); and apoptosis-inhibition (flow cytometric apoptosis assay; $P<0.05$; Fig. 2b). Furthermore, there was an increase in migration (wound healing assay; Fig. 3a) and invasion (Transwell cell migration assay; Fig. 3b). Real-time RT-PCR and Western blotting also showed increased expression of Wnt5a, p70s6k, survivin and VEGF, in REG4- transfectants or cells treated with recombinant protein compared to control and mock cells, while the converse was observed for Bax expression (Fig. 3c and d).

As determined by real-time RT-PCR, REG4 mRNA levels were higher in benign ovarian tumors than those in normal ovarian tissue $(P<0.001$; Fig. $4 \mathrm{a})$; and higher in primary carcinoma than in normal ovarian tissue ( $P=0.048$; Fig. 4a). Expression of REG4 mRNA was also higher in mucinous benign tumors than serous benign tumors $(P=0.03$; Fig. $4 \mathrm{~b})$, and in mucinous carcinoma than serous carcinoma $(P<0.001$; Fig. $4 \mathrm{~b})$, and in welland moderately-differentiated compared to poorlydifferentiated carcinomas $(P=0.011$; Fig. 4c); however, there was no correlation between REG4 mRNA expression and FIGO staging $\left(\mathrm{R}^{\wedge} 2=0.022, \quad P=0.225\right.$; Fig. 4d), and between REG4 mRNA expression and age $(P=0.06$; Additional file 1: Table S2).

Immunostaining revealed that REG4 was strongly expressed in the cytoplasm of serous and mucinous adenoma, serous and mucinous borderline tumors, serous and mucinous adenocarcinoma, and adenocarcinoma in the omentum; but was not expressed in the fiber cells of normal ovarian tissue and only very weakly in the fallopian tube (Fig. 5). As shown in Table 1, REG4 protein expression was detectable in normal ovarian tissue $(23.1 \%, 6 / 26)$, benign ovarian tumors $(70 \%, 7 / 10)$, borderline ovarian tumors $(81.8 \%, 18 / 22)$, primary cancer $(50.6 \%, 119 / 235)$ and metastatic carcinoma in the omentum $(61.4 \%, 27 / 44)$. REG4 expression was significantly higher in benign tumors, borderline tumors and primary cancer than that in normal ovarian tissue $(P<0.05$; Table 1$)$, 


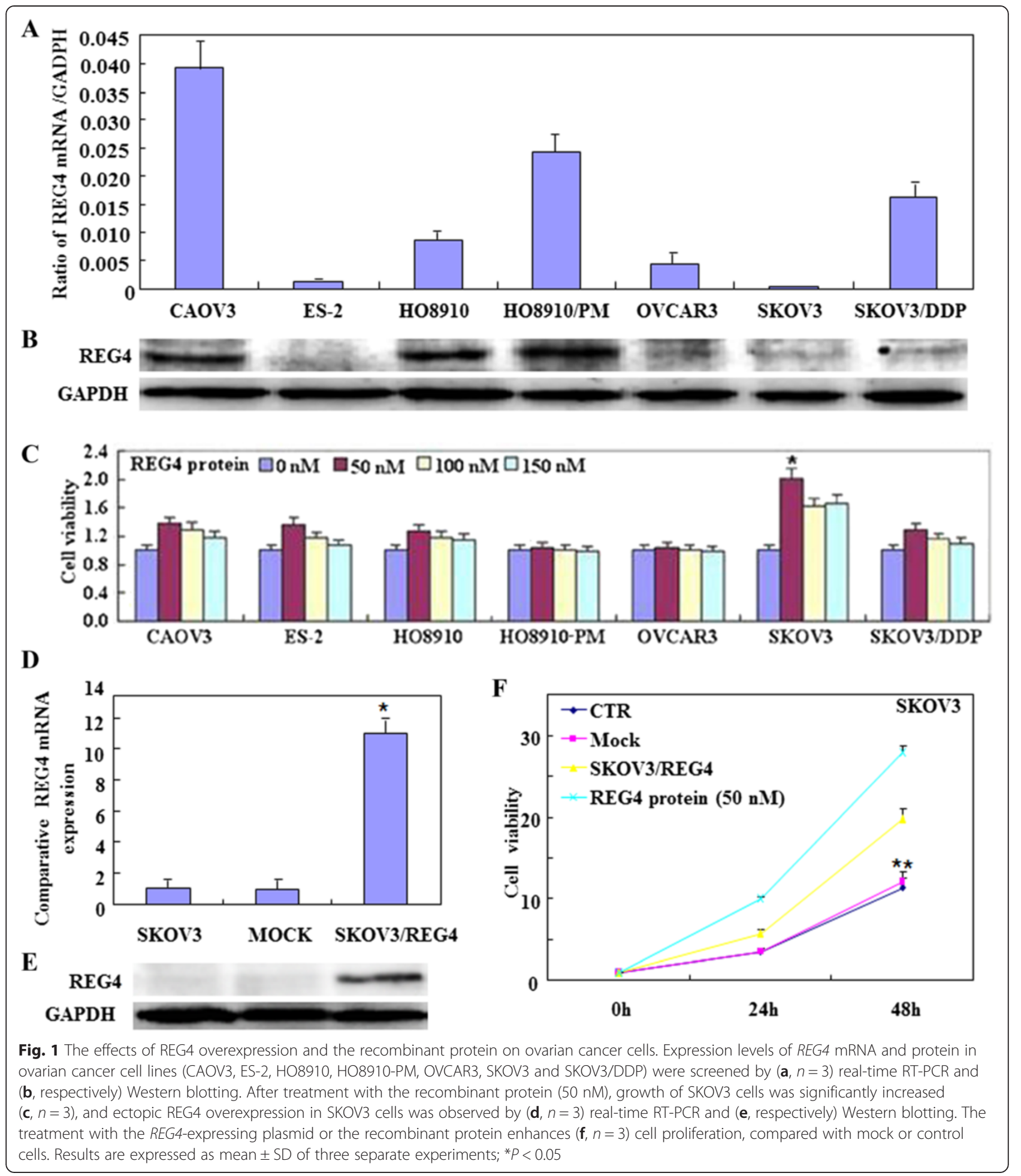

while there was no significant difference between primary and metastatic cancers in the omentum $(P=0.076$; Table 1$)$. In addition, mucinous carcinomas showed higher REG4 expression than serous ones $(P<0.05$; Table 2$)$. REG4 expression was significantly higher in well- and moderately- differentiated tumors than in poorly-differentiated ones $(P=0.009)$, and in patients aged $\geq 56$ years than in those aged $<56$ years $(P=0.03)$, although there were no significant correlation with FIGO staging or expression of the proliferation marker, Ki-67 $(P>0.05)$. In addition, Spearman's rank correlation coefficient showed no correlation between 


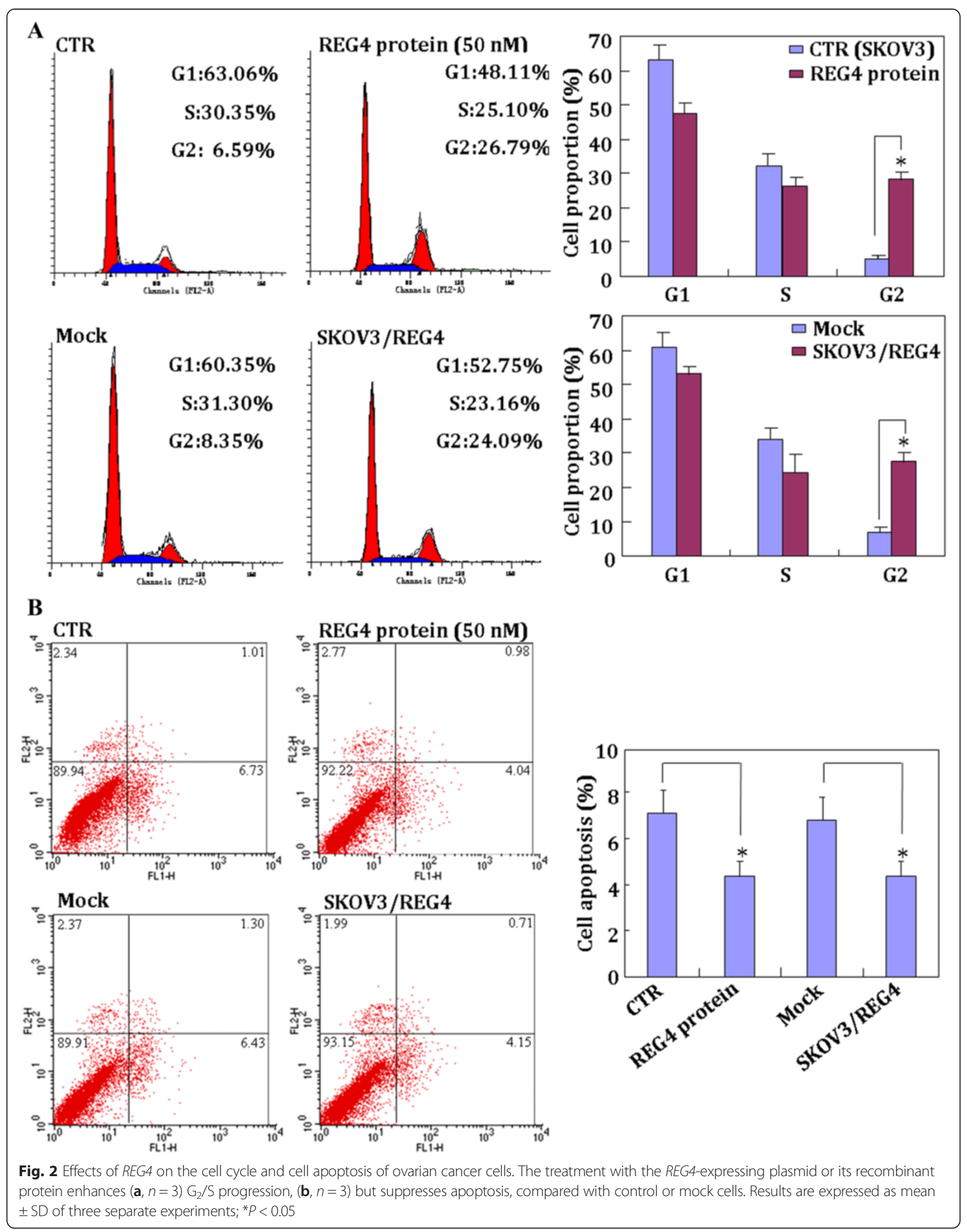




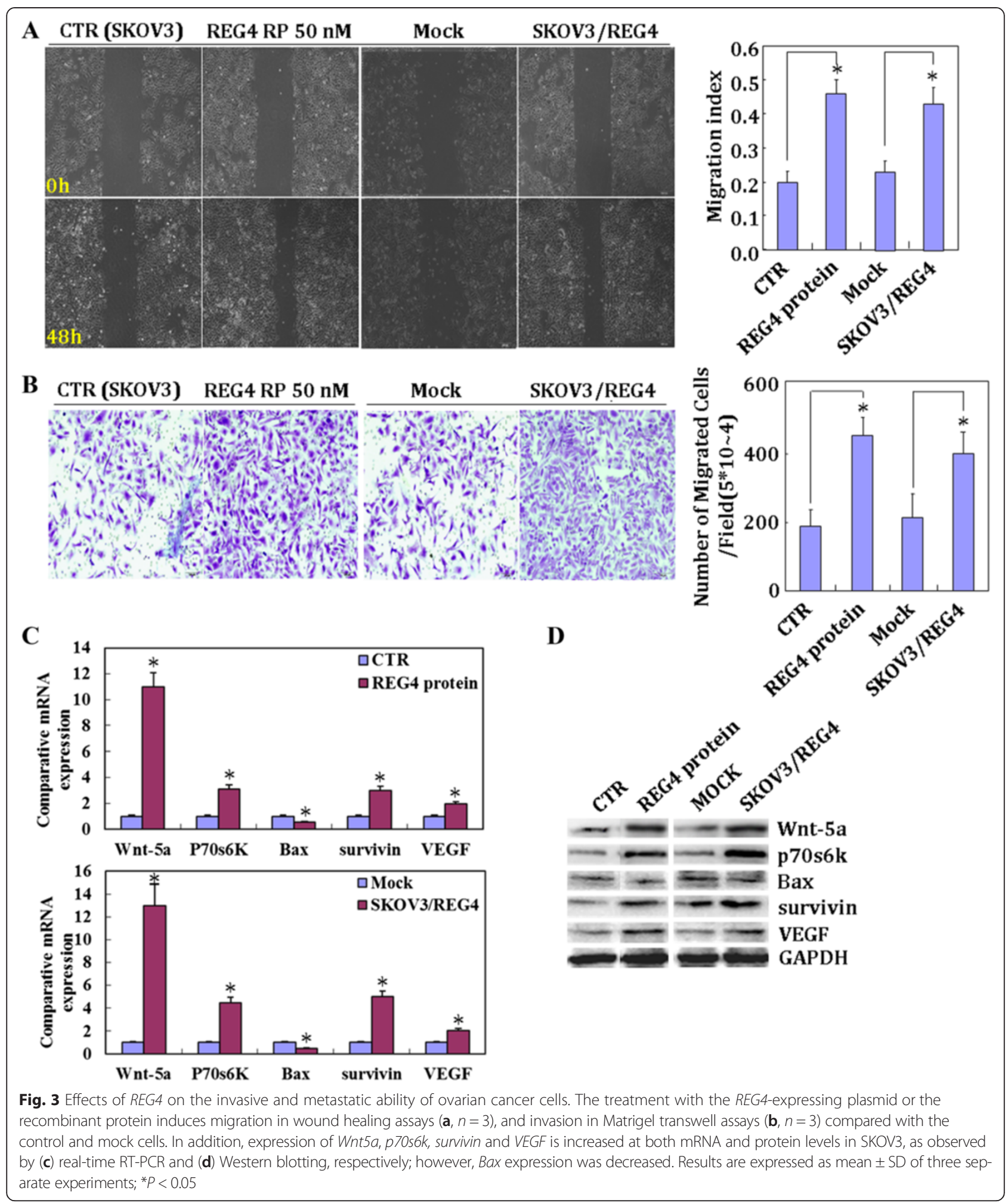

REG4 protein expression and different sample years $(r=0.0061 ; P=0.355$; Additional file 1: Table S3).

Follow-up information was available for 90 patients with ovarian cancer for periods ranging (8 lost to follow-up) from 1-103 months (median, 48 months). Survival curves for the patients with ovarian cancer were stratified according to REG4 protein expression, based on the $\mathrm{IHC}$ results (Fig. $6 \mathrm{~d} \&$ e) and subsequent univariate 

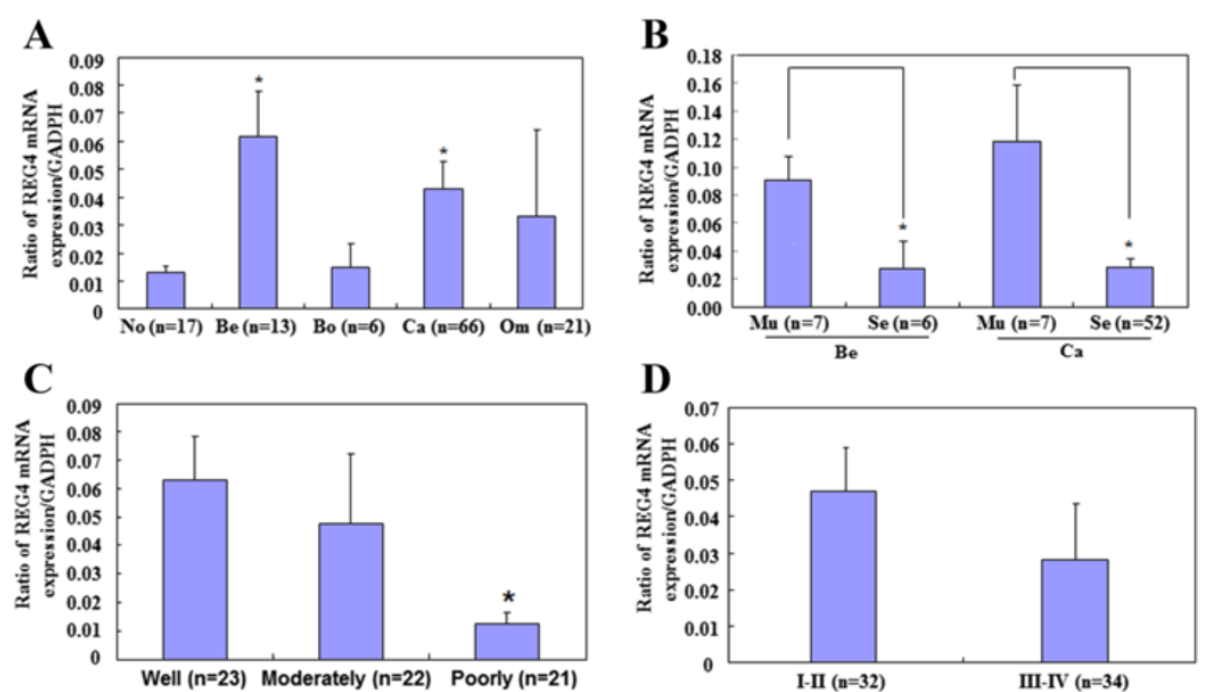

Fig. 4 Relationship between REG4 mRNA expression and clinicopathological features of ovarian cancer. REG4 mRNA expression was quantified by real-time RT-PCR in normal ovarian tissue (No; $n=17$ ), benign (Be; $n=10$ ) and borderline (Bo; $n=6)$ tumors, primary (Ca; $n=66)$ and metastatic cancers in the omentum $(\mathrm{Om} ; n=21)$. a REG4 mRNA expression levels are significantly higher in both benign ovarian tumors and primary carcinoma compared to normal ovarian tissue. b Mucinous (Mu) tumors show higher REG4 mRNA expression levels than serous (Se) tumors; and Mann-Whitney $\mathrm{U}$ test showed that REG4 mRNA expression is higher in well- and moderately-differentiated tumors than in poorly-differentiated tumors (c), but there was no significant difference between (d) FIGO staging I-II \& IIIIIV; ${ }^{*} P<0.05$

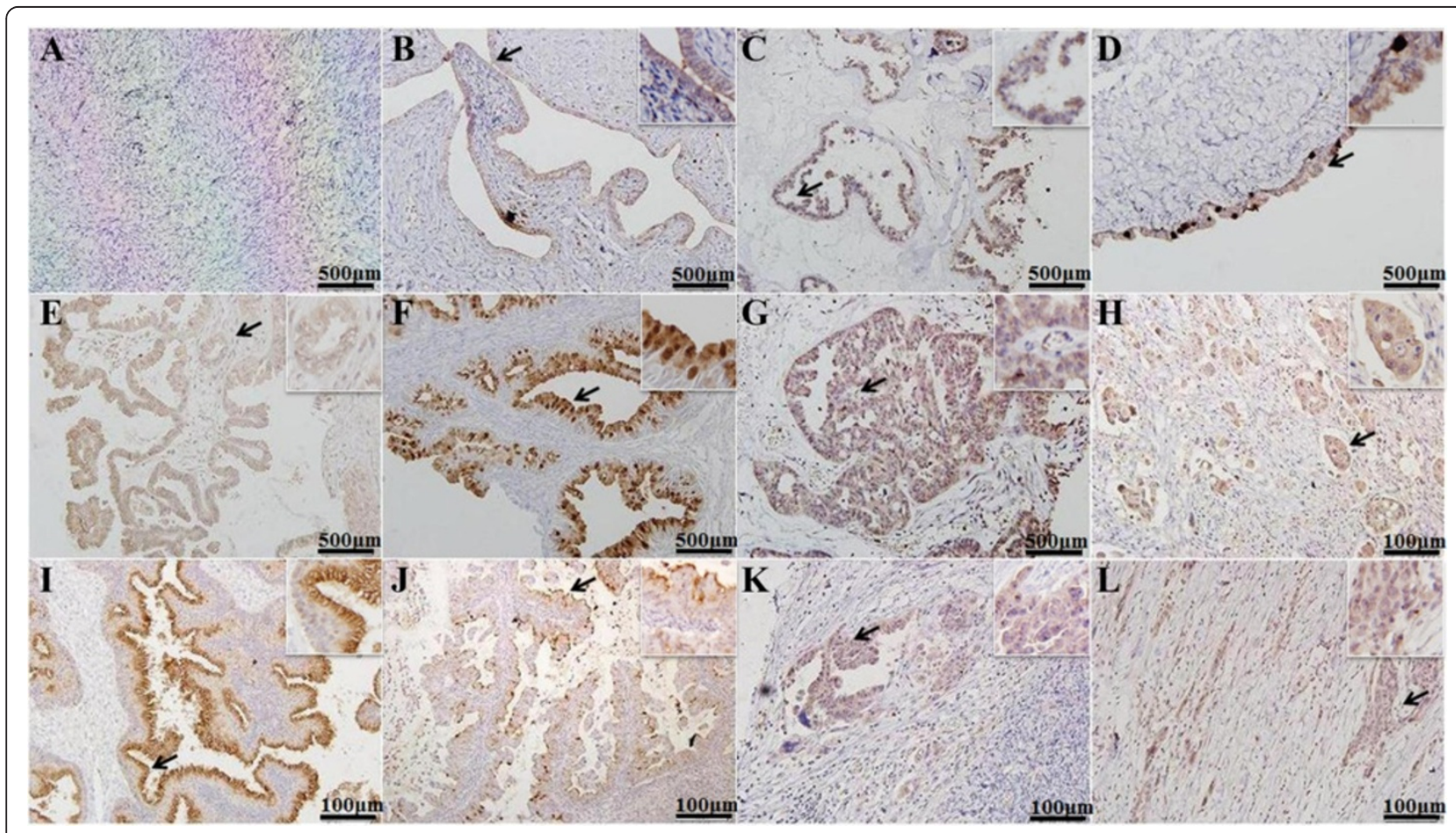

Fig. 5 Immunohistochemistry of REG4 protein expression in ovarian carcinogenesis. The micrographs show that REG4 protein is not expressed in the cytoplasm of fiber cells of normal ovary tissue (a) and only weakly in the cytoplasm of fallopian tube cells (b), but it is strongly expressed in the cytoplasm of serous and mucinous adenoma (c, $\mathbf{d})$; serous and mucinous borderline tumor $(\mathbf{e}, \mathbf{f})$; serous $(\mathbf{g}, \mathbf{h})$ and mucinous $(\mathbf{i}, \mathbf{j})$ adenocarcinoma; and adenocarcinoma in the omentum $(\mathbf{k}, \mathbf{l})$ 
Table 1 REG4 protein expression during ovarian epithelial carcinogenesis

\begin{tabular}{|c|c|c|c|c|c|c|}
\hline \multirow[t]{2}{*}{ Groups } & \multirow[t]{2}{*}{$\mathrm{n}$} & \multicolumn{5}{|c|}{ REG4 protein expression } \\
\hline & & - & + & ++ & +++ & PR (\%) \\
\hline Normal ovarian tissue & 26 & 20 & 2 & 2 & 2 & $23.1^{*}$ \\
\hline Benign ovarian tumor & 10 & 3 & 2 & 1 & 4 & 70.0 \\
\hline Borderline ovarian tumor & 22 & 4 & 2 & 2 & 14 & $81.8^{* *}$ \\
\hline Ovarian cancer & 235 & 116 & 45 & 41 & 33 & 50.6 \\
\hline Metastatic cancer in omentum & 44 & 17 & 9 & 12 & 6 & 61.4 \\
\hline \multirow[t]{2}{*}{ Groups } & \multirow[t]{2}{*}{$\mathrm{n}$} & \multicolumn{5}{|c|}{ REG4 protein expression } \\
\hline & & - & + & ++ & +++ & PR (\%) \\
\hline Primary ovarian cancer & 34 & 7 & 9 & 10 & 8 & $79.4^{\#}$ \\
\hline Metastatic cancer in omentum & 34 & 12 & 9 & 10 & 3 & 64.7 \\
\hline
\end{tabular}

$\mathrm{PR}$, positive rate

${ }^{*} P<0.05$ (normal ovarian tissue compared with benign tumor and primary carcinoma)

${ }^{*} P<0.01$ (ovarian borderline tumor compared with normal ovarian tissue) ${ }^{\#} P=0.076$ (metastatic lesions compared with relative primary cancer tissues)

analysis using Kaplan-Meier method indicated an inverse relationship between REG4 expression and cumulative $(P=0.038)$ or relapse-free survival rate $(P=0.033)$. Multivariate analysis using Cox's proportional hazard model indicated that FIGO staging $(P=0.038)$, differentiation $(P=$ $0.007)$ and REG4 expression $(P=0.006)$ were independent prognostic factors for overall survival of the patients with ovarian cancer (Table 3); whereas patient age, remnant foci size, pathological classification or serum CA-125 levels were not $(P>0.05$; Table 3$)$. Of all these parameters, only REG4 expression was found to be an independent prognostic factor of relapse-free survival of the patients with ovarian cancer $(P=0.013)$, while patient age, pathological classification, degree of differentiation, remnant foci size, serum CA-125 level and FIGO staging were not $(P>0.05$, Table 3$)$.

\section{Discussion}

Previous reports have shown that REG4 mRNA is strongly expressed in inflamed epithelium, dysplasia and cancerous lesions of ulcerative colitis [17], and REG4 overexpression has been observed in gastric, colorectal, pancreatic, hepatocellular and prostate cancers [5, 9-14]. Here, real-time PCR showed that REG4 mRNA was overexpressed in both benign ovarian tumors and cancers. Furthermore, immunohistochemistry showed that REG4 expression was increased in benign tumors, borderline tumors and primary carcinoma compared to normal ovarian tissue. This was consistent with our previous observations in gastric [13] and colorectal [14] cancers. Taken together, these

Table 2 Relationship between REG4 protein expression and clinicopathological features of ovarian cancers

\begin{tabular}{|c|c|c|c|c|c|c|c|}
\hline \multirow[t]{2}{*}{ Clinicopathological features } & \multirow[t]{2}{*}{$\mathrm{n}$} & \multicolumn{6}{|c|}{ REG4 protein expression } \\
\hline & & - & + & ++ & +++ & PR (\%) & $P$-value \\
\hline Age (years) & & & & & & & $0.03^{*}$ \\
\hline$<56$ & 115 & 63 & 25 & 15 & 12 & 45.2 & \\
\hline$\geq 56$ & 120 & 53 & 20 & 26 & 21 & 55.8 & \\
\hline Pathological classification & & & & & & & $0.009^{* *}$ \\
\hline Mucinous adenocarcinoma & 26 & 7 & 6 & 3 & 10 & $73.1^{*}$ & \\
\hline Serous adenocarcinoma & 174 & 93 & 29 & 35 & 17 & 46.6 & \\
\hline Miscellaneous subtypes & 35 & 16 & 10 & 3 & 6 & 54.3 & \\
\hline FIGO staging & & & & & & & 0.485 \\
\hline$|-| \mid$ & 87 & 47 & 15 & 10 & 15 & 46.0 & \\
\hline III-IV & 148 & 69 & 30 & 31 & 18 & 53.4 & \\
\hline Differentiation & & & & & & & $0.001^{* * *}$ \\
\hline Well-differentiated & 59 & 21 & 15 & 11 & 12 & 64.4 & \\
\hline Moderately-differentiated & 89 & 39 & 17 & 19 & 14 & 56.2 & \\
\hline Poorly-differentiated & 87 & 56 & 13 & 11 & 7 & 35.6 & \\
\hline Ki-67 expression & & & & & & & 0.419 \\
\hline- & 56 & 32 & 10 & 7 & 7 & 42.9 & \\
\hline+ & 34 & 13 & 7 & 10 & 4 & 61.8 & \\
\hline++ & 34 & 18 & 6 & 7 & 3 & 47.1 & \\
\hline+++ & 33 & 16 & 7 & 6 & 4 & 51.5 & \\
\hline
\end{tabular}

${ }^{*} P<0.05$, which were pointed out by bold text, indicate statistically significant 


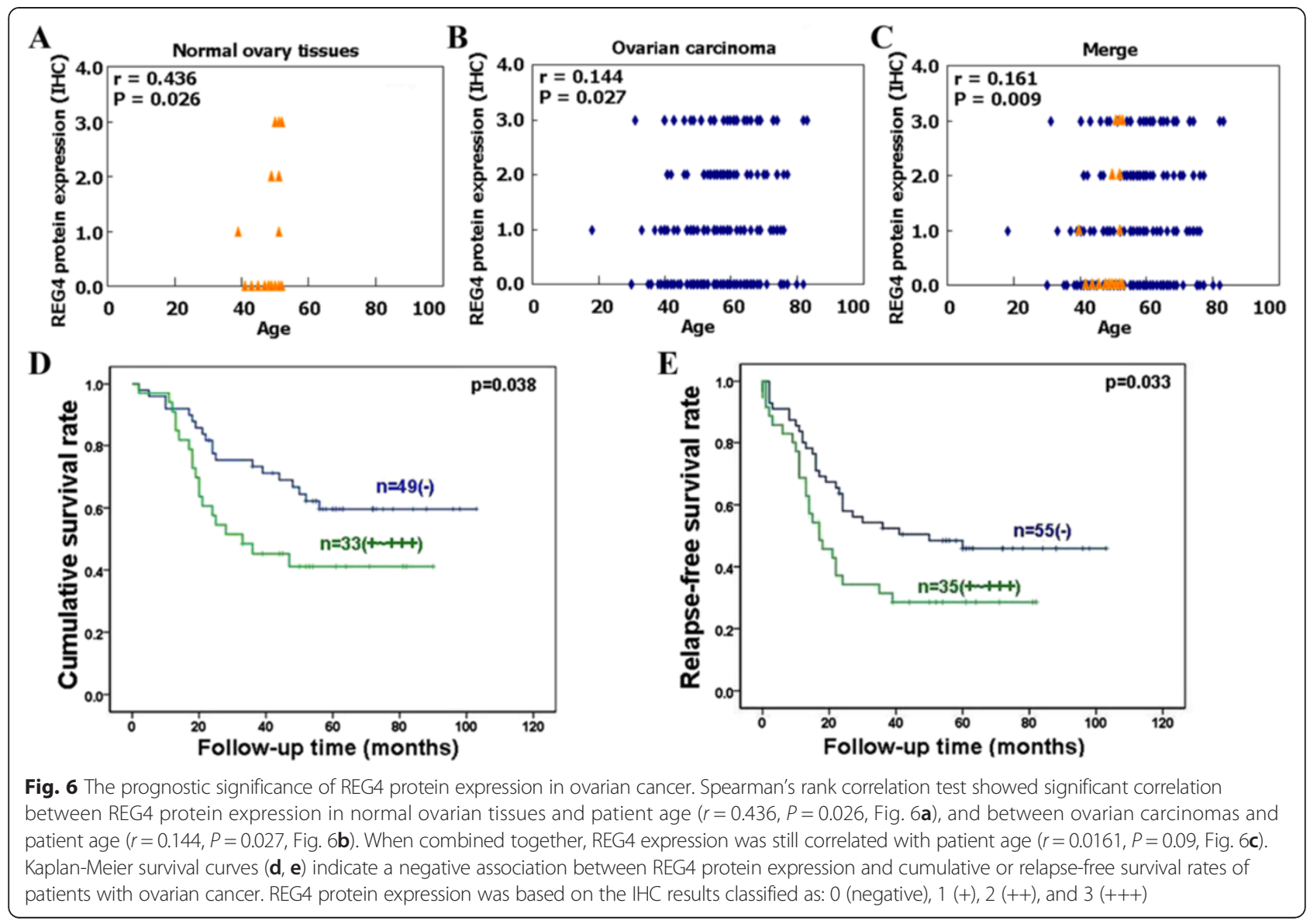

observations suggest that REG4 overexpression plays an essential role as an early event in ovarian carcinogenesis.

We found that REG4 mRNA and protein expression levels in ovarian cancer were significantly higher in mucinous tumors than in serous tumors, and were positively associated with differentiation. Again, this is consistent with our previous findings in gastric cancer, which showed positive REG4 expression in signet ring cells, and mucinous carcinoma, and higher expression in well- and moderately-differentiated adenocarcinoma than poorly-differentiated adenocarcinoma [13]. In addition, REG4 mRNA expression was higher in mucinous benign tumors and carcinomas compared to relative serous subtypes, while there was no significant difference in REG4 mRNA expression between mucinous benign tumors and mucinous carcinomas, and between serous benign tumors and serous carcinomas. Huang et al. reported that REG4 expression was also overexpressed in mucinous borderline tumors and primary mucinous carcinomas [18]. Taken together, these results suggest that

Table 3 Multivariate analysis of clinicopathological parameters with the overall survival of patients with ovarian cancer

\begin{tabular}{|c|c|c|c|c|}
\hline \multirow[t]{2}{*}{ Clinicopathological parameters } & \multicolumn{2}{|l|}{ Cumulative survival } & \multicolumn{2}{|l|}{ Relapse-free survival } \\
\hline & Relative risk $(95 \% \mathrm{Cl})$ & $P$-value & Relative risk $(95 \% \mathrm{Cl})$ & $P$-value \\
\hline Age ( $\geq 56$ years) & $1.926(0.916-4.050)$ & 0.084 & $1.784(0.963-3.306)$ & 0.066 \\
\hline Pathological subtypes (serous carcinoma) & $0.854(0.329-2.221)$ & 0.747 & $0.731(0.329-1.625)$ & 0.442 \\
\hline FIGO staging (III-IV) & $2.762(1.058-7.214)$ & 0.038 & $1.619(0.745-3.520)$ & 0.224 \\
\hline Differentiation degree (poor) & $3.007(1.350-6.700)$ & 0.007 & $1.892(0.988-3.622)$ & 0.054 \\
\hline REG4 expression $(+$ to +++$)$ & $3.057(1.369-6.827)$ & 0.006 & $2.282(1.189-4.380)$ & 0.013 \\
\hline Remnant foci size $(\geq 1 \mathrm{~cm})$ & $2.343(0.995-5.519)$ & 0.051 & $1.834(0.869-3.872)$ & 0.112 \\
\hline Serum CA-125 level ( $\geq 500)$ & $0.813(0.402-1.645)$ & 0.564 & $1.004(0.556-1.812)$ & 0.989 \\
\hline
\end{tabular}

Abbreviation: $\mathrm{Cl}=$ confidence interval

$P<0.05$, which were pointed out by bold text, indicate statistically significant 
REG4 overexpression is closely linked to the pathogenesis of ovarian mucinous carcinoma and differentiation of ovarian cancer. Furthermore, our observations revealed no significant difference in REG4 mRNA or protein expression between stages I-II and III-IV ovarian cancer, which was also consistent with our previous findings in gastric cancer [13]. Conversely, primary prostate cancers $(\mathrm{PCa})$ have been reported to express low levels of REG4 mRNA, whereas the majority of metastatic PCa tumors expressed high levels [19], and REG4 expression has been associated with lymph node metastasis, recurrence of liver metastasis and tumor stage in colorectal carcinoma [7, 20]. REG4 mRNA expression levels in surgically resected specimens and the peritoneal wash were closely related to those in wall-penetrating gastric carcinoma.

Recently, secretory REG4 protein was found to act as a potent activator of the EGFR/Akt/AP-1 signaling pathway, through phosphorylation of EGFR $[9,21]$. To elucidate the role and molecular mechanisms of REG4 in ovarian cancer cells, SKOV3 cells were transfected with REG4-expressing plasmids or exposed to recombinant REG4. We found that G2/S progression, apoptotic inhibition, proliferation, migration and invasion were significantly increased. Further investigation showed that both treatments increased expression of Wnt5a, p70s6k, survivin and VEGF at both the mRNA and proteins levels, but $B a x$ expression was decreased. Wnt5a, p70s6k, survivin, VEGF and Bax are involved in the EGFR signaling pathway, apoptosis, invasion and metastasis in malignancies. Therefore, these findings suggest that increased REG4 protein expression, or its ectopic overexpression, promotes aggressive behaviors in ovarian cancer cells by modulating expression of phenotyperelated genes [22-26]. Our results are supported by reports pf previous in vitro and in vivo experiments showing that REG4 inhibits apoptosis by increasing the expression of $B c l-2, B c l-x l$ and survivin $[9,10]$.

Although REG4 has been reported to be significantly correlated with aggressive biological behaviors of malignancies $[7,20]$, the prognostic relevance of REG4 expression remains controversial. Both previous reports found no relationship between REG4 expression and survival of patients with gastric cancer [13, 24]. In contrast, Ohara et al. [20] revealed that REG4 expression was significantly associated with longer relapse-free survival of $\mathrm{PCa}$ patients and acted as an independent prognostic factor in PCa. In accordance with previous reports on gliomas [15] and CRC [7], we found an inverse relationship between REG4 expression and cumulative or relapsefree survival rate of patients with ovarian cancer. Our multivariate model indicates that REG4 expression, FIGO staging and differentiation are independent prognostic factors of overall survival in the patients with ovarian cancer.
REG4 expression was also shown to be an independent prognostic factor of relapse-free survival.

\section{Conclusions}

REG4 expression was upregulated in precancerous ovarian lesions, then marginally downregulated as the ovarian epithelial cells underwent malignant transformation. Overexpression of REG4 protein increased the aggressiveness of ovarian cancer, as indicated by reduced apoptosis and increased proliferation, migration and invasion. We speculate that this may be correlated with the altered expression of Wnt5a, p70s6k, survivin, VEGF and Bax. Furthermore, REG4 expression was closely linked with mucinous tumors, differentiation and adverse prognosis of ovarian cancer. Taken together, our findings suggest that REG4 represents an independent indicator of poor prognosis in ovarian cancer.

\section{Additional file}

Additional file 1: Table S1. Proportion of the tumor types in different categories. Table S2. Relationship between REG4 mRNA expression and clinicopathological features of ovarian carcinomas. Table S3. REG4 protein expression during different years among ovarian epithelial carcinogenesis. Table S4. Primer sequences used for real-time RT-PCR.

\section{Abbreviations}

REG: Regenerating; P70s6k: p70 ribosomal S6 kinase; VEGF: Vascular endothelial growth factor; GAPDH: Glyceraldehyde-3-phosphate dehydrogenase; TGF: Transforming growth factor; EGFR/Akt/AP-1: Epidermal growth factor receptor/Akt kinase/activator protein-1; EGF: Epidermal growth factor; FGF: Fibroblast growth factor; HGF: Hepatocyte growth factor; MUC-2: Mucin 2, oligomeric mucus/gel-forming; FIGO: The International Federation of Gynecology and Obstetrics.

\section{Competing interests}

The authors declare that they have no competing interests.

\section{Authors' contributions}

HCZ YZ conceived the study, wrote the first and final draft of the manuscript, and analyzed interpretation. SC, WFG, SZ and ZFN carried out the experiments and analyzed the data. YT gave many good suggestions about data processing and manuscript. All authors read and approved the final manuscript.

\section{Acknowledgements}

We thank Prof. Akira Sugawara of the Department of Advanced Biological Sciences for Regeneration, Tohoku University, Graduate School of Medicine, Sendai 980-8575, Japan, for kindly providing Plasmid pCI-REG4. This project study was supported by Scientific Research Fund of Liaoning Provincial Education Department (L2010633; LU2014093); Liaoning Science and Technology Grant (2009225008-11); the Natural Scientific Foundation of China (Nos. 81172371; 81202049; 81472544).

\section{Author details}

${ }^{1}$ Department of Gynecology, The First Affiliated Hospital of China Medical University, Shenyang 110001, China. ${ }^{2}$ Department of Biochemistry and Molecular Biology, College of Basic Medicine, China Medical University, Shenyang 110001, China. ${ }^{3}$ Clinical Cancer Institute, Kanagawa Cancer Center, Yokohama 241-0815, Japan.

Received: 21 August 2014 Accepted: 13 May 2015

Published online: 16 June 2015 


\section{References}

1. Piek JM, van Diest PJ, Verheijen RH. Ovarian carcinogenesis: an alternative hypothesis. Adv Exp Med Biol. 2008;622:79-87.

2. Bandera CA. Advances in the understanding of risk factors for ovarian cancer. J Reprod Med. 2005;50(6):399-406.

3. Zhang YW, Ding LS, Lai MD. Reg gene family and human diseases. World J Gastroenterol. 2003;9:2635-41.

4. Nata K, Liu Y, Xu L, Ikeda T, Akiyama T, Noguchi N, et al. Molecular cloning, expression and chromosomal localization of a novel human REG family gene, REG III. Gene. 2004;340:161-70.

5. Zheng HC, Sugawara A, Okamoto H, Takasawa S, Takahashi H, Masuda S, et al. Expression profile of the REG gene family in colorectal carcinoma. J Histochem Cytochem. 2011;59(1):106-15.

6. Hartupee JC, Zhang H, Bonaldo MF, Soares MB, Dieckgraefe BK. Isolation and characterization of a cDNA encoding a novel member of the human regenerating protein family: Reg IV. Biochim Biophys Acta. 2001;1518:287-93.

7. Oue N, Kuniyasu H, Noguchi T, Sentani K, Ito M, Tanaka S, et al. Serum concentration of Reg IV in patients with colorectal cancer: overexpression and high serum levels of Reg IV are associated with liver metastasis. Oncology. 2007;72(5-6):371-80.

8. Enroth $\mathrm{S}$, Andersson $\mathrm{R}$, Bysani $\mathrm{M}$, Wallerman $\mathrm{O}$, Termén $\mathrm{S}$, et al. Nucleosome regulatory dynamics in response to TGF $\beta$. Nucleic Acids Res. 2014:42(11):6921-34

9. Bishnupuri KS, Luo Q, Murmu N, Houchen CW, Anant S, Dieckgraefe BK. Reg IV activates the epidermal growth factor receptor/Akt/AP-1 signaling pathway in colon adenocarcinomas. Gastroenterology. 2006;130:137-49.

10. Bishnupuri KS, Luo Q, Sainathan SK, Kikuchi K, Sureban SM, Sabarinathan M, et al. Reg IV regulates normal intestinal and colorectal cancer cell susceptibility to radiation-induced apoptosis. Gastroenterology. 2010;138(2):616-26. 626.e1-2.

11. Naito Y, Oue N, Hinoi T, Sakamoto N, Sentani K, Ohdan H, et al. Reg IV Is a direct target of intestinal transcriptional factor CDX2 in gastric cancer. PLoS One. 2012;7(11), e47545.

12. Li YG, Ji DF, Zhong S, Zhu JX, Chen S, Hu GY. Anti-tumor effects of proteoglycan from Phellinus linteus by immunomodulating and inhibiting Reg IV/EGFR/Akt signaling pathway in colorectal carcinoma. Int J Biol Macromol. 2011;48(3):511-7.

13. Zheng HC, Xu XY, Yu M, Takahashi H, Masuda S, Takano Y. The role of Reg IV gene and its encoding product in gastric carcinogenesis. Hum Pathol. 2010;41(1):59-69.

14. Li XH, Zheng Y, Zheng HC, Takahashi H, Yang XH, Masuda S, et al. REG IV overexpression in an early stage of colorectal carcinogenesis: an immunohistochemi- cal study. Histol Histopathol. 2010;25(4):473-84.

15. Wang Q, Deng J, Yuan J, Wang L, Zhao Z, He S, et al. Oncogenic reg IV is a novel prognostic marker for glioma patient survival. Diagn Pathol. 2012:7(1):69.

16. Kumada T, Tsuneyama K, Hatta H, Ishizawa S, Takano Y. Improved 1-h rapid immunostaining method using intermittent microwave irradiation: practicability based on 5 years application in Toyama Medical and Pharmaceutical University Hospital. Mod Pathol. 2004;17:1141-9.

17. Nanakin A, Fukui H, Fujii S, Sekikawa A, Kanda N, Hisatsune $H$, et al. Expression of the REG IV gene in ulcerative colitis. Lab Invest. 2007;87:304-14.

18. Huang Q, Chen X, Lu W, Lai M, Lu B. Expression of REG4 in Ovarian Mucinous Tumors. Appl Immunohistochem Mol Morphol. 2013;16.

19. Ohara S, Oue N, Matsubara A, Mita K, Hasegawa Y, Hayashi T, et al. Reg IV is an independent prognostic factor for relapse in patients with clinically localized prostate cancer. Cancer Sci. 2008;99:1570-7.

20. Oue N, Mitani Y, Aung PP, Sakakura C, Takeshima Y, Kaneko M, et al. Expression and localization of Reg IV in human neoplastic and nonneoplastic tissues: Reg IV expression is associated with intestinal and neuroendocrine differentiation in gastric adenocarcinoma. J Pathol. 2005:207:185-98.

21. Mitani Y, Oue N, Matsumura S, Yoshida K, Noguchi T, Ito M, et al. Reg IV is a serum biomarker for gastric cancer patients and predicts response to 5fluorouracil-based chemotherapy. Oncogene. 2007;26:4383-93.

22. Zhao Y, Chen S, Gou WF, Niu ZF, Zhao S, Xiao LJ, et al. The role of EMMPRIN expression in ovarian epithelial carcinomas. Cell Cycle. 2013;12(17):2899-913.

23. Nishita M, Enomoto M, Yamagata K, Minami Y. Cell/tissue-tropic functions of Wnt5a signaling in normal and cancer cells. Trends Cell Biol. 2010;20(6):346-54.
24. Zheng H, Takahashi H, Murai $Y$, Cui Z, Nomoto K, Niwa H, et al. Expressions of MMP-2, MMP-9 and VEGF are closely linked to growth, invasion, metastasis and angiogenesis of gastric carcinoma. Anticancer Res. 2006:26(5A):3579-83

25. Li J, Wang H, Ma Z, Fan W, Li Y, Han B, et al. TAT-Apoptin induces apoptosis in the human bladder cancer EJ cell line and regulates Bax, Bcl-2, caspase-3 and survivin expression. Exp Ther Med. 2012;3(6):1033-8.

26. Xiao L, Wang YC, Li WS, Du Y. The role of mTOR and phospho-p70S6K in pathogenesis and progression of gastric carcinomas: an immunohistochemical study on tissue microarray. J Exp Clin Cancer Res. 2009;28:152.

\section{Submit your next manuscript to BioMed Central and take full advantage of:}

- Convenient online submission

- Thorough peer review

- No space constraints or color figure charges

- Immediate publication on acceptance

- Inclusion in PubMed, CAS, Scopus and Google Scholar

- Research which is freely available for redistribution 